\title{
Micronutrient intakes, micronutrient status and lipid profiles among young people consuming different amounts of breakfast cereals: further analysis of data from the National Diet and Nutrition Survey of Young People aged 4 to 18 years
}

\author{
Sigrid Gibson* \\ SiG-Nurture Nutrition Consultancy, 11 Woodway, Guildford, Surrey, GU1 2TF, UK
}

Submitted 19 February 2003: Accepted 28 May 2003

\begin{abstract}
Objective: To examine associations between breakfast cereal consumption and the dietary habits, nutrient intakes and nutritional status of young people, considering both nutrient adequacy and safety issues (fortification).

Methods: Using archived data from 1688 children in the (British) National Diet and Nutrition Survey of Young People aged 4 to 18 years, nutrient intakes and status were compared across thirds of breakfast cereal consumption (T1 to T3), adjusted for age and energy intake. Cereals provided on average $2 \%, 6 \%$ and $12 \%$ of energy in T1, T2 and T3, respectively, for boys; $1 \%, 4 \%$ and $10 \%$, respectively, for girls.

Results: Intakes of iron, B vitamins and vitamin D were around $20-60 \%$ higher in $\mathrm{T} 3$ compared with T1, with significant linear relationships observed for iron, thiamin, riboflavin and folate $(\mathrm{T} 1<\mathrm{T} 2<\mathrm{T} 3)$. After excluding low energy reporters and the unwell, $14 \%$ of girls had iron intakes below the Lower Reference Nutrient Intake and this varied fivefold between T1 and T3 $(27 \%, 12 \%$ and $5 \% ; P=0.0001)$. High consumers of breakfast cereals (T3) had better folate, vitamin $\mathrm{B}_{12}$ and riboflavin status and lower total and low-density lipoprotein cholesterol. There was also an association with thiamin and vitamin $\mathrm{B}_{6}$ status in girls. However, iron status (haemoglobin, ferritin and transferrin saturation) was not significantly different between groups, possibly due to lower meat intakes in T3. Total iron intakes were within tolerable levels (maximum of $32 \mathrm{mg} \mathrm{day}{ }^{-1}$ in one girl taking supplements).

Conclusions: The nutritional benefits of breakfast cereals are demonstrated in status measurements as well as in nutrient intakes in this study. Concerns about excessive iron intakes from fortification appear unjustified.
\end{abstract}

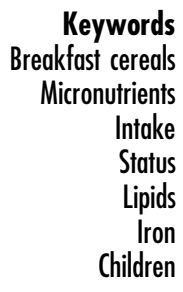

The micronutrient density of young people's diets today may be greater than previously, as a result of the fortification of many staple cereal products and particularly breakfast cereals ${ }^{1}$. These make a substantial contribution to daily intakes of B vitamins and iron ${ }^{2}$, and studies have shown that children (and adults) who consume above-average quantities of cereals tend to have superior micronutrient intakes ${ }^{3-7}$. Some studies have shown evidence of a link with micronutrient status, especially of B vitamins ${ }^{8}$. A direct impact of fortified foods on folate status has also been shown in intervention studies $^{9,10}$.

Despite these encouraging associations with vitamin intake and status, a link between cereal consumption and iron status has been less easy to demonstrate. This reflects the poor correlation between total iron intake and status, which arises partly because absorption is increased when iron stores are low, and partly because absorption varies with the form of iron (haem/non-haem) and the presence of other dietary components (enhancers or inhibitors) ${ }^{11}$. Using data from a nation-wide study of pre-school children ( 1.5 to 4.5 years $)^{12}$, for example, no association was found between cereal consumption and iron status (ferritin or haemoglobin level), which was hypothesised to have been due to the lower intakes of meat and vitamin C among high consumers of breakfast cereals ${ }^{5}$. Work with stable isotopes has quantified the bioavailability of iron from breakfast cereals at around 3\%, although this is doubled if a source of ascorbic acid is consumed in the same meal ${ }^{13}$.

In parallel with the concerns about nutrient inadequacy in this age group, there is some controversy about the potential for excessive intakes as a result of fortification practices $^{14,15}$. The aim of the present study was to examine both the positive and the potential negative impacts of breakfast cereal consumption on micronutrient status, 
using data from the most recent nation-wide study of young people aged 4 to 18 years in Britain.

\section{Methods}

The National Diet and Nutrition Survey of Young People aged 4 to 18 years (NDNS 4-18) is part of a rolling programme of government-funded surveys, which cover the free-living population of Britain (England, Wales and Scotland) every $12-15$ years. At the interview stage, detailed information is collected on background factors and household circumstances, diet and lifestyle, food avoidance, illness and medications. Of the 2127 young people interviewed for the survey of young people in 1998, weighed dietary records of all food and drink consumed over seven consecutive days were obtained from 1701 (80\%). Subsequently, physical measurements were taken and a blood sample for assessment of nutritional status was obtained from 1193 (60\%) of those originally interviewed. Details of the procedures followed and the analytical methods used for nutritional assessments are given in the main report ${ }^{2}$.

\section{Data analysis and statistical methods}

Assessment of dietary intakes was based on the diary sample of 1701, less 13 children for whom some data on nutrient intakes were missing. Thus our final sample consisted of 1688 children ( 851 boys and 837 girls) ranging from 4 to 18 years (mean age 11 years). To adjust for the wide range of ages and energy intakes in this survey, breakfast cereal consumption (defined as all varieties, both ready-to-eat and oats/muesli) was calculated as a percentage of total dietary energy, and then tertiles were calculated separately for each year of age, within each sex. Girls and boys in each year group were then classified into thirds of the distribution: T1 (lowest 33.3\%), T2 (middle $33.3 \%$ ) and $\mathrm{T} 3$ (highest 33.3\%), so that the resulting groups had an equal age-sex distribution. The lowest third included both non-consumers and those who ate around 1 or 2 portions a week. It was not feasible to treat non-consumers as a separate group because unequal age distribution would have created bias.

Differences between high, medium and low consumers of cereals were evaluated by one-way analysis of variance (ANOVA), with the Bonferroni test for multiple comparisons, or by the $t$-test (two-tailed) for two-group comparisons. Non-parametric methods (Kruskal-Wallis ANOVA and Mann-Whitney $U$-test) were used where the variables were not normally distributed (e.g. food intakes). Values of $P<0.05$ were taken as statistically significant, with exact significance quoted. For comparison of body mass index (BMI), equations based on UK reference curves (Child Growth Foundation) were used to compute each child's $Z$-score and percentile for BMI (i.e. the deviation from their age- and sex-specific median). The proportion of children in each group who were overweight and obese was then calculated using cut-offs suggested by the working party of the International Obesity Task Force/European Childhood Obesity Group ${ }^{16,17}$. The cut-offs suggested for the UK are $Z$-scores of $>1.3$ (boys) and $>1.19$ (girls) for overweight and $>2.35$ (boys) and $>2.27$ (girls) for obesity, which correspond to the adult criteria of $>25 \mathrm{~kg} \mathrm{~m}^{-2}$ and $>30 \mathrm{~kg} \mathrm{~m}^{-2}$, respectively, extrapolated back to child$\operatorname{hood}^{18}$.

\section{Results}

\section{Consumption of breakfast cereals and contribution to energy and micronutrient intakes}

The distribution of breakfast cereal consumption is shown expressed as a percentage of energy in Fig. 1. Boys consumed proportionately more cereal than girls (mean $7 \%$ of energy vs. $5 \%$ among girls; $P<0.0001)$. In T3, cereals provided on average $10 \%$ of energy for girls $(678 \mathrm{~kJ}$ $\mathrm{day}^{-1}$ ) and $12 \%$ of energy for boys $\left(937 \mathrm{~kJ} \mathrm{day}^{-1}\right)$. This is equivalent to about $30 \mathrm{~g}$ and $40 \mathrm{~g}$ of cereal per day, respectively. For low/non-consumers in T1, cereals provided less than $2 \%$ of the average energy intake (Table 1).

Breakfast cereals are nutrient-dense and made a substantial contribution to intakes of B vitamins, vitamin $\mathrm{D}$ and iron, compared with energy. For example, among girls, cereals provided only $5 \%$ of the total energy intake but $21 \%$ of the iron, $18 \%$ of the folate, thiamin and riboflavin, $16 \%$ of the vitamin $\mathrm{D}, 15 \%$ of the vitamin $\mathrm{B}_{6}$ and $13 \%$ of the niacin. Among boys the contributions were higher, consistent with their higher intake.

\section{Associations between cereal consumption level and total nutrient intakes}

Low consumers of cereal (T1) had significantly lower intakes than other children of five B vitamins (thiamin,

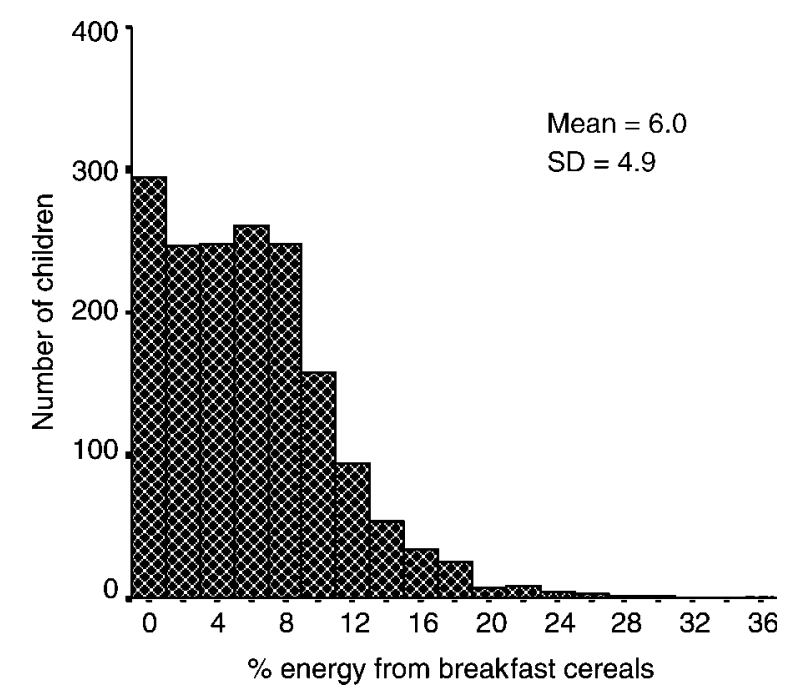

Fig. 1 Percentage of energy from breakfast cereals: distribution for all children $(n=1688)$. SD - standard deviation 
riboflavin, niacin, $\mathrm{B}_{6}$ and folic acid), plus iron and vitamin $\mathrm{D}$. Compared with intakes in T1, iron intakes in T3 were 42\% higher among girls and 33\% higher among boys. Intakes of $\mathrm{B}$ vitamins (thiamin, riboflavin, niacin, vitamin $\mathrm{B}_{6}$, vitamin $\mathrm{B}_{12}$ and folate) and also vitamin $\mathrm{D}$ were around $20-60 \%$ higher in T3 compared with T1, with significant linear relationships observed for thiamin, riboflavin and folate $(\mathrm{T} 1<\mathrm{T} 2<\mathrm{T} 3)$. Higher calcium intakes among moderate-to-high consumers of cereals (T2 and T3) are mostly attributable to a higher consumption of milk, and this also contributed to the differences in riboflavin and zinc intakes between the groups (Tables 2 and 3).

Table 1 Mean percentage of energy from breakfast cereals, by third of consumption

\begin{tabular}{lcccrr}
\hline & \multicolumn{5}{c}{$\begin{array}{c}\text { Third of cereal } \\
\text { consumption } \\
\text { (age-adjusted) }\end{array}$} \\
\cline { 3 - 5 } Age group (years) & $n$ & 1 & 2 & 3 & Total \\
\hline Boys & & & & & \\
$\quad 4-6$ & 183 & 2.9 & 6.8 & 11.5 & 7.1 \\
$7-10$ & 256 & 2.5 & 6.7 & 12.4 & 7.2 \\
$11-14$ & 233 & 1.2 & 6.4 & 12.4 & 6.8 \\
$15-18$ & 179 & 0.5 & 4.7 & 12.5 & 5.9 \\
$\quad$ Group total & 851 & 1.8 & 6.2 & 12.2 & 6.8 \\
Girls & & & & & \\
$\quad 4-6$ & 171 & 2.6 & 5.9 & 10.8 & 6.5 \\
$7-10$ & 225 & 1.2 & 4.9 & 10.2 & 5.5 \\
$11-14$ & 234 & 0.6 & 4.4 & 11.2 & 5.5 \\
$15-18$ & 207 & 0.0 & 2.1 & 8.4 & 3.5 \\
Group total & 837 & 1.0 & 4.4 & 10.2 & 5.2 \\
\hline
\end{tabular}

Table 2 Total mean intakes of energy and nutrients, by third of cereal consumption (boys)

\begin{tabular}{|c|c|c|c|c|c|}
\hline & \multicolumn{3}{|c|}{$\begin{array}{l}\text { Third of cereal } \\
\text { consumption }\end{array}$} & \multirow{2}{*}{$\begin{array}{c}P \text {-value } \\
\text { (ANOVA) }\end{array}$} & \multirow{2}{*}{$\begin{array}{l}\text { Bonferroni } \\
\text { post hoc test }\end{array}$} \\
\hline & 1 & 2 & 3 & & \\
\hline nergy $(\mathrm{kJ})$ & 7908 & 8218 & 7696 & 0.011 & $2>3$ \\
\hline Fat $(\mathrm{g})$ & 78 & 77 & 68 & 0.0001 & $3<1,2$ \\
\hline Protein $(\mathrm{g})$ & 61 & 63 & 60 & NS $(0.059)$ & \\
\hline Carbohydrate (g) & 248 & 266 & 257 & 0.008 & $2>1$ \\
\hline Total sugars (g) & 114 & 120 & 116 & NS & \\
\hline NMES (g) & 85 & 88 & 82 & NS & \\
\hline Sodium (mg) & 2628 & 2667 & 2536 & NS & \\
\hline Potassium (mg) & 2286 & 2412 & 2286 & 0.047 & \\
\hline Calcium (mg) & 731 & 802 & 817 & 0.0001 & $1<2,3$ \\
\hline Iron (mg) & 8.7 & 10.6 & 11.6 & 0.0001 & $1<2<3$ \\
\hline Zinc & 6.6 & 7.1 & 7.0 & 0.046 & $1<2$ \\
\hline Retinol $(\mu \mathrm{g})$ & 351 & 351 & 319 & NS & \\
\hline Carotene $(\mu \mathrm{g})$ & 1436 & 1437 & 1307 & NS & \\
\hline Thiamin (mg) & 1.4 & 1.6 & 1.8 & 0.0001 & $1<2<3$ \\
\hline Riboflavin (mg) & 1.3 & 1.8 & 2.1 & 0.0001 & $1<2<3$ \\
\hline Niacin (mg) & 26 & 30 & 31 & 0.0001 & $1<2,3$ \\
\hline Vitamin $\mathrm{B}_{6}(\mathrm{mg})$ & 1.9 & 2.2 & 2.4 & 0.0001 & $1<2<3$ \\
\hline Vitamin $B_{12}(\mu \mathrm{g})$ & 3.8 & 4.5 & 4.8 & 0.0001 & $1<2,3$ \\
\hline Folate $(\mu \mathrm{g})$ & 199 & 246 & 271 & 0.0001 & $1<2<3$ \\
\hline$C(\mathrm{mg})$ & 83 & 80 & 77 & NS & \\
\hline Vitamin $D(\mu \mathrm{g})$ & 2.4 & 3.0 & 3.0 & 0.0001 & $1<2,3$ \\
\hline
\end{tabular}

ANOVA - analysis of variance; NS - not significant; NMES - non-milk extrinsic sugars.
Table 3 Total mean intakes of energy and nutrients, by third of cereal consumption (girls)

\begin{tabular}{|c|c|c|c|c|c|}
\hline & \multicolumn{3}{|c|}{$\begin{array}{l}\text { Third of cereal } \\
\text { consumption }\end{array}$} & \multirow{2}{*}{$\begin{array}{c}P \text {-value } \\
\text { (ANOVA) }\end{array}$} & \multirow{2}{*}{$\begin{array}{l}\text { Bonferroni } \\
\text { post hoc test }\end{array}$} \\
\hline & 1 & 2 & 3 & & \\
\hline nergy (kJ) & 6482 & 6840 & 6711 & 0.017 & $1<2$ \\
\hline t & 64 & 66 & 60 & 0.0001 & $3<2,1$ \\
\hline Protein (g) & 50 & 53 & 53 & 0.011 & $1<2,3$ \\
\hline Carbohydrate (g) & 201 & 218 & 224 & 0.0001 & $1<2,3$ \\
\hline Total sugars $(\mathrm{g})$ & 92 & 101 & 100 & 0.006 & $1<2,3$ \\
\hline NMES (g) & 68 & 71 & 70 & NS & \\
\hline Sodium (mg) & 2104 & 2180 & 2236 & 0.026 & $3>2,1$ \\
\hline Potassium (mg) & 1947 & 2077 & 2085 & 0.0 & $3>1$ \\
\hline Calcium (mg) & 598 & 685 & 703 & 0.0001 & $1<2,3$ \\
\hline Iron (mg) & 7.1 & 8.5 & 10.1 & 0.0001 & $1<2<3$ \\
\hline Zinc & 5.4 & 5.9 & 6.0 & 0.0001 & $1<2,3$ \\
\hline Retinol ( $\mu \mathrm{g})$ & 276 & 295 & 307 & NS & \\
\hline Carotene $(\mu \mathrm{g})$ & 1344 & 1391 & 1353 & NS & \\
\hline Thiamin (mg) & 1.1 & 1.4 & 1.6 & 0.0001 & $1<2<3$ \\
\hline Riboflavin (mg) & 1.1 & 1.4 & 1.7 & 0.0001 & $1<2<3$ \\
\hline Niacin (mg) & 21 & 24 & 27 & 0.0001 & $1<2<3$ \\
\hline Vitamin $B_{6}(m g$ & 1.6 & 1.9 & 2.1 & 0.0001 & $1<2,3$ \\
\hline Vitamin $B_{12}(\mu \mathrm{g})$ & 3.1 & 3.5 & 3.9 & 0.0001 & $1<2,3$ \\
\hline Folate $(\mu \mathrm{g})$ & 166 & 198 & 232 & 0.0001 & $1<2<3$ \\
\hline Vitz & 75 & 79 & 78 & NS & \\
\hline Vitamin $D(\mu \mathrm{g})$ & 2.0 & 2.2 & 2.5 & 0.0001 & $1,2<3$ \\
\hline
\end{tabular}

ANOVA - analysis of variance; NS - not significant; NMES - non-milk extrinsic sugars.

\section{Prevalence of low intakes}

To evaluate the significance of cereal consumption for public health, we evaluated the percentage of individuals with nutrient intakes below their age- and sexspecific Lower Reference Nutrient Intake (LRNI) ${ }^{19}$. The LRNI defines a theoretical level (two standard deviations below the Estimated Average Requirement) at which $97.5 \%$ of individuals are unlikely to be consuming adequate amounts. Therefore prevalence figures exceeding $2.5 \%$ can be taken to indicate a potential shortfall in intakes. Whilst such children cannot be said categorically to have 'inadequate intakes' because of the uncertainties surrounding individual requirements and the measurement of diet, they can nevertheless be regarded as 'at-risk'.

Results showed that virtually all children exceeded the LRNI for thiamin, niacin and vitamin $\mathrm{B}_{6}$, but a high proportion of girls had very low intakes of iron (24\%), calcium (12\%), potassium (15\%) and riboflavin (11\%) (data not shown). Children who consumed least cereal (T1) were between two and eight times more likely to have intakes below the LRNI, compared with those in T3. For example, $42 \%$ of the girls in T1 had iron intakes below the LRNI compared with $11 \%$ of girls in T3 $(P<0.0001)$. Comparable prevalence figures for calcium were $22 \%$ vs. $9 \%$, and for riboflavin $25 \%$ vs. $3 \%$, both differences being highly statistically significant. Folate intakes were below the LRNI for $6 \%$ of girls in T1 (compared with $0 \%$ in T3). Boys showed similar trends in prevalence for iron and riboflavin, although absolute rates were much lower (e.g. 4\% and $0 \%$ for iron in $\mathrm{T} 1$ and $\mathrm{T} 3$, respectively). 


\section{Effects of potential underreporting}

Underreporting and illness that affects eating may both lead to underestimates of habitual consumption, and thus to potentially inflated prevalence estimates of children below the LRNI. To examine this, supplementary analyses were carried out after excluding the $20 \%$ of boys and $26 \%$ of girls who (1) had energy intakes that were implausibly low (ratio of energy intake to basal metabolic rate $<1.05)^{20}$ or (2) reported having an illness affecting their eating habits during the week of survey. Excluding these children halved the prevalence figures but did not reduce the significance of differences between the groups. Thus $14 \%$ of girls were found to have iron intakes below the LRNI and this varied fivefold between the groups (27\%, $12 \%$ and $5 \%$ in T1, T2 and T3, respectively; $P=0.0001)$. Similarly, $15 \%$ of girls in T1 had riboflavin intakes below the LRNI, compared with a mere $2 \%$ in T2 and $0 \%$ in T3. Calcium and potassium intakes, although less critical ( $5 \%$ of girls below the LRNI), showed the same trends, but intakes of other nutrients did not suggest cause for concern.

\section{Associations between cereal consumption level and other dietary habits}

Differences in food consumption pattern (expressed as grams of food per MJ of energy intake) were examined between high, medium and low consumers of breakfast cereals (data not shown). Most importantly in regard to iron status, high consumers of cereal (T3) ate less red meat than low consumers (T1) (boys: 9.8 vs. $11.7 \mathrm{~g} \mathrm{MJ}^{-1}$, $P=0.007$; girls: 9.1 vs. $\left.10.9 \mathrm{~g} \mathrm{MJ}^{-1}, P=0.01\right)$. Milk consumption among high consumers of cereal (T3) was twice that of low consumers (T1) $(P<0.0001)$. Boys who ate the most cereal had diets lower in bread, fats, savoury snacks, confectionery, biscuits and cakes $(P<0.05)$, and girls showed similar trends. There was no difference between groups in the consumption of fruit, fruit juice, salads or vegetables.

\section{Associations between cereal consumption level and micronutrient status}

Folate status (both serum and red-cell folate), vitamin $\mathrm{B}_{12}$ status and riboflavin status were all positively associated with breakfast cereal consumption in both sexes $(P<0.001)$. Thiamin status and vitamin $\mathrm{B}_{6}$ status (erythrocyte aspartate aminotransferase coefficient) were also positively associated with cereal consumption in girls, but not in boys. Iron status was evaluated using three indices: haemoglobin (functional iron in red blood cells), ferritin (iron stores) and transferrin saturation (transport iron). There was no evidence that high consumers of breakfast cereals had better mean iron status, or a lower prevalence of poor status, despite their higher iron intakes (Tables 4 and 5).

\section{Associations with overweight and blood lipids}

High consumers of breakfast cereals had slightly more favourable lipid profiles than low or average consumers (Table 5). Children in $\mathrm{T} 3$ had the lowest low-density lipoprotein cholesterol levels (boys: T3 $<$ T1, $P=0.008$; girls: T3 $<\mathrm{T} 2, P=0.02)$. Approximately $19 \%$ of boys and $22 \%$ of girls were overweight according to the specified criteria $^{18}$, with approximately one in five of these in the obese category. However, there were no significant differences in mean BMI or the prevalence of obesity or overweight across thirds of cereal consumption (not shown).

\section{Fortification and safety issues}

We compared iron intakes (including supplements) with suggested safe Upper Levels (ULs) from the US Food and Nutrition Board ${ }^{21}$ and the UK Food Standards Agency

Table 4 Micronutrient status by third of cereal consumption (boys)

\begin{tabular}{|c|c|c|c|c|c|c|}
\hline & \multirow[b]{2}{*}{$n$} & \multicolumn{3}{|c|}{ Third of cereal consumption } & \multirow[b]{2}{*}{ Total } & \multirow[b]{2}{*}{$P$-value (ANOVA } \\
\hline & & 1 & 2 & 3 & & \\
\hline Haemoglobin $\left(\mathrm{g} \mathrm{dl}^{-1}\right)$ & 559 & 13.6 & 13.5 & 13.6 & 13.6 & NS \\
\hline Serum ferritin $\left(\mu \mathrm{gl}^{-1}\right)$ & 449 & 45 & 37 & 41 & 41 & NS \\
\hline Transferrin saturation (\%) & 473 & 24 & 23 & 23 & 24 & NS \\
\hline ETKAC* $^{*}$ (vitamin $\left.B_{1}\right)$ & 509 & 1.12 & 1.12 & 1.11 & 1.12 & 0.079 \\
\hline${\left.\text { EGRAC* (vitamin } B_{2}\right)}^{\prime}$ & 518 & 1.49 & 1.41 & 1.36 & 1.42 & 0.0001 \\
\hline EAATAC* (vitamin $B_{6}$ ) & 518 & 1.81 & 1.79 & 1.79 & 1.80 & NS \\
\hline Serum $B_{12}\left(p m o l l^{-1}\right)$ & 551 & 365 & 402 & 435 & 401 & 0.001 \\
\hline Serum folate $\left(\mathrm{nmolI}{ }^{-1}\right)$ & 554 & 19 & 22 & 25 & 22 & 0.0001 \\
\hline Red-cell folate $\left(\mathrm{nmoll}^{-1}\right)$ & 517 & 545 & 632 & 688 & 624 & 0.0001 \\
\hline Plasma ascorbate $\left(\mu \mathrm{moll}^{-1}\right)$ & 512 & 59 & 58 & 56 & 58 & NS \\
\hline Plasma 250HD (vitamin D) (nmol I $\left.{ }^{-1}\right)$ & 516 & 60.9 & 64.7 & 65.4 & 63.8 & NS \\
\hline Total cholesterol $\left(\mathrm{mmoll}^{-1}\right)$ & 449 & 4.22 & 3.95 & 3.98 & 4.04 & 0.007 \\
\hline LDL cholesterol $\left(\mathrm{mmoll}^{-1}\right)^{\prime}$ & 449 & 2.94 & 2.73 & 2.67 & 2.78 & 0.004 \\
\hline HDL cholesterol (mmol $\left.{ }^{-1}\right)$ & 449 & 1.28 & 1.22 & 1.31 & 1.27 & 0.052 \\
\hline Triglycerides & 447 & 0.98 & 0.89 & 0.88 & 0.91 & 0.250 \\
\hline
\end{tabular}

ANOVA - analysis of variance; NS - not significant; 25OHD - 25-hydroxyvitamin D; ETKAC - erythrocyte transketolase activation coefficient; EGRAC - erythrocyte glutathione reductase activation coefficient; EAATAC - erythrocyte aspartate aminotransferase coefficient; LDL - low-density lipoprotein; HDL - high-density lipoprotein.

${ }^{*}$ High values of these indices indicate poor status. 
Table 5 Micronutrient status by third of cereal consumption (girls)

\begin{tabular}{|c|c|c|c|c|c|c|}
\hline & \multirow[b]{2}{*}{$n$} & \multicolumn{3}{|c|}{ Third of cereal consumption } & \multirow[b]{2}{*}{ Total } & \multirow[b]{2}{*}{$P$-value (ANOVA) } \\
\hline & & 1 & 2 & 3 & & \\
\hline Haemoglobin $\left(\mathrm{g} \mathrm{dl}^{-1}\right)$ & 516 & 13.0 & 13.0 & 13.0 & 13.0 & NS \\
\hline Serum ferritin $\left(\mu \mathrm{gl}^{-1}\right)$ & 394 & 33 & 32 & 30 & 32 & NS \\
\hline Transferrin saturation (\%) & 452 & 22 & 21 & 22 & 22 & NS \\
\hline ETKAC* $\left(\right.$ vitamin $\left.B_{1}\right)$ & 489 & 1.13 & 1.12 & 1.11 & 1.12 & 0.018 \\
\hline EGRAC* (vitamin $\left.B_{2}\right)$ & 492 & 1.56 & 1.48 & 1.42 & 1.49 & $<0.0001$ \\
\hline 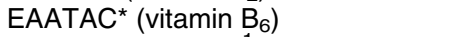 & 492 & 1.80 & 1.82 & 1.76 & 1.79 & 0.008 \\
\hline Serum $B_{12}\left(p^{\prime} I^{-1}\right)$ & 508 & 346 & 406 & 407 & 385 & 0.001 \\
\hline Serum folate (nmoll ${ }^{-1}$ ) & 509 & 17 & 21 & 23 & 20 & $<0.0001$ \\
\hline Red-cell folate $\left(\mathrm{nmoll}{ }^{-1}\right)$ & 479 & 487 & 555 & 635 & 559 & $<0.0001$ \\
\hline Plasma ascorbate $\left(\mu \mathrm{moll}^{-1}\right)$ & 484 & 59 & 59 & 60 & 59 & NS \\
\hline Plasma 25OHD (vitamin D) $\left(\mathrm{nmoll}^{-1}\right)$ & 490 & 59 & 61 & 62 & 61 & NS \\
\hline Total cholesterol $\left(\mathrm{mmoll}^{-1}\right)$ & 420 & 4.22 & 4.32 & 4.06 & 4.20 & 0.028 \\
\hline LDL cholesterol $\left(\mathrm{mmoll}^{-1}\right)^{\prime}$ & 420 & 2.96 & 3.04 & 2.77 & 2.92 & 0.021 \\
\hline HDL cholesterol (mmoll-1 $)$ & 420 & 1.26 & 1.28 & 1.28 & 1.28 & NS \\
\hline Triglycerides & 420 & 0.96 & 1.01 & 0.96 & 0.98 & NS \\
\hline
\end{tabular}

ANOVA - analysis of variance; NS - not significant; $25 \mathrm{OHD}$ - 25-hydroxyvitamin D; ETKAC - erythrocyte transketolase activation coefficient; EGRAC - erythrocyte glutathione reductase activation coefficient; EAATAC - erythrocyte aspartate aminotransferase coefficient; LDL - low-density lipoprotein; HDL - high-density lipoprotein.

${ }^{*}$ High values of these indices indicate poor status.

Expert Group on Vitamins and Minerals (EVM) ${ }^{22}$. The EVM considered that insufficient evidence was available to set a Safe Upper Level (SUL), but gave a guidance level of $17 \mathrm{mg}$ day $^{-1}$ from supplements. American ULs are $40 \mathrm{mg} \mathrm{day}^{-1}$ for children aged 9-13 years and $45 \mathrm{mg}$ day $^{-1}$ for adolescents aged $14-18$ years.

Maximal iron intake over the seven days of survey was $32 \mathrm{mg} \mathrm{day}{ }^{-1}$, and therefore below the American ULs. Overall, $40-45 \%$ of the variance in iron intakes was explained by cereal-derived iron. Only $2 \%$ ( 47 children) were taking iron supplements, including the girl with the highest iron intake $\left(32 \mathrm{mg}\right.$ day $\left.^{-1}\right)$ who was taking a supplement containing around $26 \mathrm{mg} \mathrm{day}^{-1}$. None of the other supplement users derived more than $14 \mathrm{mg} \mathrm{day}^{-1}$ from this source.

\section{Discussion}

There appears to be a linear relationship between cereal consumption and diet quality, such that children who eat above-average quantities of cereal had higher total intakes of iron, B vitamins and vitamin D. Low intakes of iron and riboflavin were common among girls and cereal consumption was associated with less risk of inadequate intakes. Thus, after exclusion of low energy reporters, $27 \%$ of girls who consumed the least breakfast cereal (T1) had iron intakes below the LRNI, compared with only 5\% of T3. In T1, 15\% had riboflavin intakes below the LRNI, compared with none in T3.

Our analyses suggest that children who eat little in the way of breakfast cereals make up the energy deficit with either a bread-based breakfast or snacks such as crisps, biscuits and soft drinks, or by consuming more food at other meals. Overall, these substitutions led to inferior intakes of the $\mathrm{B}$ vitamins, vitamin $\mathrm{D}$, iron and calcium. Fruit and vegetable consumption differed little, while one less desirable attribute of high cereal consumption was the lower consumption of red meat.

Blood analyses confirmed the superior B vitamin status of high cereal consumers, but a significant association with iron status could not be demonstrated. This is most likely to be due to the lower meat intakes of high cereal consumers in this survey. Other cross-sectional studies have also failed to demonstrate a positive association between cereal consumption and iron status, and some have even reported an inverse association. For example, in a study of 487 middle-aged women, Kato et al. found that serum ferritin levels were inversely associated with breakfast cereal consumption ${ }^{23}$. Meat consumption may have been a confounder in that study, since a positive association between meat and serum ferritin was noted.

There is a theoretical risk that consumption of very high quantities of fortified foods may result in excessive intakes of some micronutrients ${ }^{14,15,24}$. The development of safe upper intake levels (UL) for micronutrients is now being pursued at an international level. For B vitamins (with the exception of vitamin $\mathrm{B}_{6}$ ) there is little evidence of harm, but high intakes of divalent minerals are of more concern. In particular, excessive iron intakes could potentiate the risk of iron overload (increased body iron stores) in individuals with hereditary haemochromatosis ${ }^{25}$. Our analysis suggests that excessive iron intake is not a problem in these UK children, because no child achieved levels approaching $40 \mathrm{mg}$ day $^{-1}$. Furthermore, the statusdependent control of iron absorption implies that dietary iron overload cannot develop in normal subjects, even with diets having high iron content or high iron bioavailability $^{26}$.

In conclusion, the nutritional benefits of breakfast cereal consumption are demonstrated in status measurements and lipid profiles as well as nutrient intakes in this study. However, the higher iron intakes of high cereal consumers 
were not accompanied by better iron status, probably because these were counteracted by lower meat consumption, which reduced iron bioavailability. There is a need to improve iron status among girls and young women, especially in those who are vegetarian. This can be best achieved through a combination of: (1) a sufficient food intake (since energy intake is the best predictor of micronutrient intake), (2) iron-rich foods (including fortified cereal products) and (3) optimised bioavailability (including a source of vitamin $\mathrm{C}$ and avoiding drinking tea with meals). Iron supplementation may be warranted among some children with poor eating habits or excessive iron losses, but this should preferably be taken on medical advice and following haematological investigations.

\section{Acknowledgements}

Material from the National Diet and Nutrition Survey of Young People aged 4-18 years, carried out on behalf of the Ministry of Agriculture, Fisheries and Food and the Department of Health, has been used by permission of the Controller of The Stationery Office. Views expressed are those of the author (S.G.). Financial support for the present study was provided by Kellogg's.

\section{References}

1 Serra-Majem L. Vitamin and mineral intakes in European children. Is food fortification needed? Public Health Nutrition 2001; 4(1A): 101-7.

2 Gregory J, Lowe S, National Diet and Nutrition Survey: Young People aged 4 to 18 years. Vol. 1. Report of the Diet and Nutrition Survey. Office of the Population Censuses and Surveys, Social Survey Division. London: HMSO, 2000.

3 Gibson SA, O'Sullivan K. Breakfast cereal consumption patterns and nutrient intakes of British schoolchildren. Journal of the Royal Society of Health 1995; 115(6): 366-70.

4 McNulty H, Eaton-Evans J, Cran G, Woulahan G, Boreham C, Savage JM, et al. Nutrient intakes and impact of fortified breakfast cereals in schoolchildren. Archives of Disease in Childhood 1996; 75(6): 474-81.

5 Gibson SA. Iron intake and iron status of preschool children: associations with breakfast cereals, vitamin $\mathrm{C}$ and meat. Public Health Nutrition 1999; 2(4): 521-8.

6 Ortega RM, Requejo AM, Redondo R, Lopez-Sobaler AM, Andres P, Ortega A, et al. Influence of the intake of fortified breakfast cereals on dietary habits and nutritional status of Spanish schoolchildren. Annals of Nutrition \& Metabolism 1996; 40(3): 146-56.

7 Bertrais S, Polo Luque ML, Preziosi P, Fieux B, Torra De Flot M, Galan P, et al. Contribution of ready-to-eat cereals to nutrition intakes in French adults and relations with corpulence. Annals of Nutrition \& Metabolism 2000; 44(5-6): 249-55.

8 Preziosi P, Galan P, Deheeger M, Jacob N, Drewnowski A, Hercberg S. Breakfast type, daily nutrient intakes and vitamin and mineral status of French children, adolescents, and adults. Journal of the American College of Nutrition 1999; 18(2): $171-8$.
9 Cuskelly GJ, McNulty H, Scott JM. Effect of increasing dietary folate on red-cell folate: implications for prevention of neural tube defects. Lancet 1996; 347(9002): 657-9.

10 Cuskelly GJ, McNulty H, Scott JM. Fortification with low amounts of folic acid makes a significant difference in folate status in young women: implications for the prevention of neural tube defects. American Journal of Clinical Nutrition 1999; 70(2): 234-9.

11 Ashwell MA, ed. Iron. Nutritional and Physiological Significance. British Nutrition Foundation Task Force. London: British Nutrition Foundation, 1995.

12 Gregory J, Collins D, Davies P, Hughes J, Clarke P. National Diet and Nutrition Survey: Children aged 1.5 to 4.5 years. Vol. 1. Report of the Diet and Nutrition Survey. Office of the Population Censuses and Surveys, Social Survey Division. London: HMSO, 1995.

13 Fairweather-Tait S, Fox T, wharf SG, Eagles J. The bioavailability of iron in different weaning foods and the enhancing effect of a fruit drink containing ascorbic acid. Pediatric Research 1995; 37(4): 389-94.

14 Schumann K. Safety aspects of iron in food. Annals of Nutrition \& Metabolism 2001; 45(3): 91-101.

15 Whittaker P, Tufaro PR, Rader JI. Iron and folate in fortified cereals. Journal of the American College of Nutrition 2001; 20(3): 247-54.

16 Bellizzi MC, Dietz WH. Workshop on childhood obesity: summary of the discussion. American Journal of Clinical Nutrition 1999; 70(1): 173S-5S.

17 Dietz WH, Bellizzi MC. Introduction: the use of body mass index to assess obesity in children. American Journal of Clinical Nutrition 1999; 70(1): 123S-5S.

18 Cole TJ, Bellizzi MC, Flegal KM, Dietz WH. Establishing a standard definition for child overweight and obesity worldwide: international survey. British Medical Journal 2000; 320(7244): 1240-3.

19 Department of Health. Dietary Reference Values for Food Energy and Nutrients for the United Kingdom. London: HMSO, 1991.

20 Black AE. Critical evaluation of energy intake using the Goldberg cut-off for energy intake:basal metabolic rate. A practical guide to its calculation, use and limitations. International Journal of Obesity and Related Metabolic Disorders 2000; 24(9): 1119-30.

21 Food and Nutrition Board, Institute of Medicine. Dietary Reference Intakes for Vitamin A, Vitamin K, Arsenic, Boron, Chromium, Copper, Iodine, Iron, Manganese, Molybdenum, Nickel, Silicon, Vanadium, and Zinc. Washington, DC: National Academy Press, 2001.

22 Food Standards Agency. Safe Upper Levels of Vitamins and Minerals. Expert Group on Vitamins and Minerals. London: The Stationery Office, 2003.

23 Kato I, Dnistrian AM, Schwartz M, Toniolo P, Koenig K, Shore $\mathrm{RE}$, et al. Risk of iron overload among middle-aged women. International Journal for Vitamin and Nutrition Research 2000; 70(3): 119-25.

24 Walter P. Towards ensuring the safety of vitamins and minerals. Toxicology Letters 2001; 120(1-3): 83-7.

25 Marx JJ. Iron deficiency in developed countries: prevalence, influence of lifestyle factors and hazards of prevention. European Journal of Clinical Nutrition 1997; 51(8): 491-4.

26 Hulten L, Gramatkovski E, Gleerup A, Hallberg L. Iron absorption from the whole diet. Relation to meal composition, iron requirements and iron stores. European Journal of Clinical Nutrition 1995; 49(11): 794-808. 